\title{
Comparative study of laparoscopic pyelolithotomy versus percutaneous nephrolithotomy in the management of large renal pelvic stones
}

\author{
Yasser M. Haggag, MD; GamalMorsy, MD; Magdy M. Badr, MD; ${ }^{*}$ Abdel Baset A. Al Emam, MD; \\ Mourad Farid, MD, ${ }^{*}$ Mohamed Etafy, $M D^{+}$
}

*Al-Azhar Urology Department, Assiut, Egypt; † Jackson Hospital, Miami, FL

Cite as: Can Urol Assoc J 2013;7:E171-E175. http://dx.doi.org/10.5489/cuaj.490

\section{Abstract}

Background: The aim of the study is to investigate whether laparoscopic pyelolithotomy (LPL) could be used to manage large renal pelvic stones, generally considered excellent indications for percutaneous nephrolithotomy (PNL).

Methods: This study was performed from May 2009 to March 2012 at Al-Azhar University Hospitals (Assiut and Cairo), Egypt. It included two groups of patients with large renal pelvic stones; only patients with stones $2.5 \mathrm{~cm}^{2}$ or greater were included. Group 1 included 40 patients treated by PNL and Group 2 included 10 patients treated by LPL. The differences between the two procedures were compared and analyzed.

Results: There was no difference between the two groups regarding patient demographics and stone size. There was a statistically significant difference between the groups regarding mean estimated blood loss $(65 \pm 12.25$ [range: $52.75-77.25$ ] vs. $180 \pm 20.74$ [range: $159.26-200.74] \mathrm{mL}, p \leq 0001)$, mean hospital stay $(2.3 \pm$ 0.64 [range: $1.66-2.94$ ] vs. $3.7 \pm 1.4$ [range: $2.3-5.1$ ] days, $p \leq 0.006)$, rate of postoperative blood transfusion ( $0 \%$ vs. $4.8 \%$, $p \leq 0.0024)$, and stone-free rate $(80 \%$ vs. $78.6 \%, p \leq 0.23)$. The mean operative time was significantly longer in Group 2 (LPL) $(131 \pm 22.11$ [range: $108.89-153.11)$ vs. $51.19 \pm 24.39$ [range: 26.8-75.58] min, $p \leq 0001$ ), respectively.

Conclusion: Although PNL is the standard treatment in most cases of renal pelvic stones, LPL is another feasible surgical technique for patients with large renal pelvic stones.

\section{Introduction}

With the advances in shock wave lithotripsy (SWL) and endourological procedures, such as percutaneous nephrolithotomy (PNL) and ureterorenoscopy (URS), the treatment of urinary stone disease has changed markedly. The indications for open renal surgery to treat renal calculi are limited to special situations; it is needed in only $0.47 \%$ to $5.4 \%$ of the time. ${ }^{1-4}$ To treat renal calculi of $2.5 \mathrm{~cm}^{2}$ or larger in diameter, PNL has been used successfully. With low complication rates, PNL has been accepted as first-line therapy. ${ }^{5}$
According to the guidelines, laparoscopic pyelolithotomy (LPL) is indicated when endoscopic procedures fail, if there is a complex stone burden, renal and anatomical abnormalities, or if there are indications for open surgery. ${ }^{5}$

There are some advantages to laparoscopy despite to its rarity and limited indications. However, advanced experience and high skills are needed for the laparoscopic management of complex stones, such as anatrophric nephrolithotomy. ${ }^{6,7}$ With the increase in stone size, success, complications and additional treatment rates differ in patients treated with PNL. ${ }^{8}$

In centres with established experience in advanced reconstructive laparoscopy, LPL can be a feasible alternative to PNL. ${ }^{9}$ In this study, we compared PNL versus LPL in large pelvic stone and investigated the role of LPL.

\section{Methods}

From May 2009 to March 2012, 10 patients with large renal pelvic calculi $\left(2.5 \mathrm{~cm}^{2}\right.$ or more) were treated with LPL. In the same period, PNL was performed in 42 patients (2 patients had staged bilateral PNL and we therefore excluded from the analysis). An informed written consent was taken from each patient.

All patients were documented prospectively in our database. We tallied age, stone location and size. Preoperative complete blood count, serum creatinine, platelet count, bleeding and coagulation profile and urine analysis were obtained from all patients. Radiological evaluation included intravenous urography (IVU) and ultrasonography (U/S), with the addition of non-contrast computed tomography (CT) in cases of radiolucent stones. The degree of hydronephrosis was assessed according to the Society for Fetal Urology (SFU) Classification. ${ }^{10}$

The stone burden was determined by radiographic studies, the stone surface area (SA) was calculated by tracing the stone on a KUB (kidney, ureter, bladder) film in the anteroposterior view then using the formula: $S A=L x W x$ $\varpi \times 0.25(\varpi=3.14159) .{ }^{11}$ 


\section{Technique of LPL}

Under general anesthesia and while in the lithotomy position, the patient initially had an open-ended ureteral catheter placed, through which a guide wire was inserted up to the renal pelvis. The patient was then moved to the fullflank position and the table was flexed for retroperitoneal approach. A standard retroperitoneoscopic approach was applied as described by Rassweiler and colleagues. ${ }^{12}$

After the dissection of the renal pelvis, we performed a longitudinal or curvilinear pyelolithotomy incision according to the size and shape of the stone. After pyelotomy was created, the stone within the renal pelvis was removed intact and placed in a specimen retrieval bag using the stone forceps. After the calculi were removed, a double-J stent was inserted over the guide wire advanced into the renal pelvis under laparoscopic vision.

A 4-0 polyglactin suture was used to close the pyelolithotomy from the proximal to the distal edge of the incision in a running fashion. A suction drain was passed through the lateral port and placed in the peripelvic tissues, under endoscopic guidance. In the transperitoneal approach, the patient was placed in a 30 to 45 degrees modified lateral decubitus position with minimal flexion and attached to the operating table with padded fixators. In patients with ureteropelvic junction (UPJ) concomitant to renal pelvis stone, a standardized laparoscopic Anderson -Hynes dismembered pyeloplasty was performed as previously described. ${ }^{13}$

\section{Technique of PNL}

A standardized PNL procedure was performed in all cases as described elsewhere. ${ }^{14}$ To summarize, a 5-French ureteral catheter was placed initially while the patient was in a lithotomy position and under general anesthesia. Percutaneous access was obtained by the surgeon under guidance of $\mathrm{C}$-armed fluoroscopy. The tract was dilated with a high-pressure NephroMax (Boston Scientific, Natick, MA) balloon dilator using a LeVeen inflator (Boston Scientific, Natick, MA) and a 30 French Amplatz sheath (Cook Medical, Bloomington, IN) placed over the inflated NephroMax under fluoroscopic guidance. Nephroscopy was performed with a rigid 26 French nephroscope. Stone fragmentation was accomplished using a pneumatic lithotripter.

Fragments were removed with graspers. Additional tracts were created when indicated in the same session. Stone clearance and the integrity of the collecting system were confirmed intraoperatively by fluoroscopic screening and antegrade nephrostography.

At the end of the procedure, a 14 French nephrostomy tube was placed in all patients. In the presence of ureteropelvic junction obstruction (UPJO), a full-thickness incision was made using a hook knife truly lateral to the UPJ. A 6
French double-J stent was inserted at the end of the procedure. Initial postoperative stone-free rates were determined by patient assessment at the time of hospital discharge with KUB radiography.

The postoperative stone-free rate was determined at 3 months postoperatively, using a spiral CT. The procedure was considered successful if the patient was stone free.

We tallied the data of patients with renal pelvic stones managed with LPL and PNL (Table 1). Statistical analysis of this study was done by Microsoft Excel 2010 and PASW statistics program version 18.0.0 (Runs Test, Skewness, Kurtosis and T-test) and the interpretation of results at http://www. easycalculation.com/statistics/statistics.php. A p value $>0.10$ was not significant, $\leq 0.05$ to $<0.10$ marginally significant, $\leq 0.01$ to $\leq 0.05$ significant and $\leq 0.001$ highly significant.

\section{Results}

The mean patient age was $38.8 \pm 12.17$ years (range: 26.63-50.97) and $42.03 \pm 13.17$ years (range: $28.86-55.2$ ) in the LPL and PNL groups, respectively $(p \leq 0.413)$. The mean stone size was $6.5 \pm 1.20 \mathrm{~cm}^{2}$ (range: $5.3-7.7$ ) and $4.19 \pm 2.03 \mathrm{~cm}^{2}$ (range: $2.16-6.22$ ) in the LPL and PNL groups, respectively $(p \leq 0.328)$. We tallied the rate of congenital anomalies in both groups (Table 1). We also compared perioperative parameters (Table 2). The mean operation time was significantly prolonged in the LPL group than in the PNL group, $131 \pm 22.11$ minutes (range: 108.89153.11 ) versus $51.19 \pm 24.39$ minutes (range: $26.8-75.58$ ) $(p \leq 0.0001)$.

In the PNL group, 33 (78.6\%), patients were stone-free, while $9(21.4 \%)$ had residual stones; in the LPL group, $8(80 \%)$ patients were stone-free, while $2(20 \%)$ had residual stones $(p \leq 0.23)$. SWL was the treatment of choice for the management of residual stones throughout the study, except for $4.8 \%$ of patients in the PNL group who were treated by URS.

In the PNL group the complication rate was $35.7 \%$. One patient $(2.5 \%)$ had high-grade fever (Clavien 1$)$. Bleeding (Clavien 1) occurred in 2 patients $(4.8 \%)$. The first patient bled early on postoperatively and was managed conservatively by occlusion of the PNL tube for 6 hours and blood transfusion; the second patient had secondary hemorrhage (Clavien 2) 7 days after being discharged and was managed by blood transfusion. Perforation of the pelvicaleceal system occurred in 2 patients $(4.8 \%)$ and was managed conservatively in both patients. In the LPL group, the complication rate was 30\%; patients had high-grade fever (Clavien 2) and 3 days paralytic ileus (this was recorded in 3 patients, mostly due to the intraperitoneal migration of small stones); all cases were resolved conservatively. The mean blood loss was $65 \pm 12.25 \mathrm{~mL}$ (range: $52.75-77.25$ ) in the LPL group as compared to $180 \pm 20.74 \mathrm{~mL}$ (range: $159.26-200.74$ ) in the PNL group and were statistically significant $(p \leq 0001)$. 


\begin{tabular}{|c|c|c|c|}
\hline & LPL & PNL & $p$ value \\
\hline No. procedures & 10 & 42 & N/A \\
\hline Mean age \pm SD & $38.8 \pm 12.17$ years & $42.03 \pm 13.17$ years & $<0.413$ \\
\hline Sex & 5 (males) and 5 (females) & 31 (males) and 9 (females) & N/A \\
\hline Stone size \pm SD & $6.5 \pm 1.20 \mathrm{~cm}^{2}$ & $4.19 \pm 2.03 \mathrm{~cm}^{2}$ & $<0.328$ \\
\hline Associated anomalies & $\begin{array}{c}\text { Ectopic pelvic kidney (1) } \\
\text { Ectopic pelvic kid. + PUJO (1) }\end{array}$ & $\begin{array}{l}\text { Malrotated (2) } \\
\text { Horseshoe (1) }\end{array}$ & N/A \\
\hline
\end{tabular}

LPL: laparoscopic pyelolithotomy; PNL: percutaneous nephrolithotomy; SD: standard deviation; PUJO: pelvi-ureteric junction obstruction; N/A; not applicable.

However, blood transfusion was required for 2 patients (4.8\%) in the PNL group. The hospitalization period was significantly shorter in the LPL group, $2.3 \pm 0.64$ days (range: 1.66-2.94) versus $3.7 \pm 1.4$ days (range: $2.3-5.1)(p \leq 0.006)$. Upon patient request (not routinely), 6.6 morphine equivalents were given postoperatively to both groups. Analgesia was needed only for $2.2 \pm 0.9$ days (range: $1.3-3.1$ ) and $2.4 \pm 0.9$ days (range: $1.5-3.3$ ) in the PNL and LPL groups, respectively.

\section{Discussion}

$\mathrm{PNL}$ is the preferred treatment to manage renal stones that are $2 \mathrm{~cm}^{2}$ or greater. ${ }^{15}$ Although LPL was first described in the early 1990s, it did not gain popularity among urologists because of its long learning curve and the already wellestablished PNL technique. ${ }^{16}$

Recently, successful laparoscopic management of renal stones has been described; however, the indications have not yet been defined and outcomes have not been compared with established techniques, such as PNL. ${ }^{17,18}$

In the current study, LPL was evaluated as a surgical monotherapy to manage renal pelvic stones and compared with PNL. In our study, the preoperative data of both groups were homogenous with no statistically significant difference regarding age, sex and stone size.
The operative time ranged from 110 to 190 minutes (mean $131 \pm 22.11$ ), which is shorter than what Al-Azaby found (135 minutes). ${ }^{19}$ However, it is longer than the time reported by Al-Hunayan and colleagues ${ }^{18}$ (112.1 minutes) and Nouralizadeh and colleagues ${ }^{20}$ (177 minutes, range: 110-240).

Meria and colleagues ${ }^{21}$ and Goel and colleagues ${ }^{22}$ found significantly longer mean operative times for LPL than for PNL (184 vs. 139 minutes, respectively, $p=0.02$; and 142 vs. 72 minutes, respectively, $p<0.0001)$. A third non-randomized controlled trial by Gaur and colleagues ${ }^{23}$ reported a mean operative time of 116 minutes for LPL, compared with 152 minutes for PNL ( $p$ value not stated). The longer time of LPL in our study was usually related to the long learning curve of LPL as well as the time needed for intracorporeal suturing and delivery of the stone. The mean operative time of LPL in our study, however, was acceptable and average in relation to many studies..$^{21,24,25}$

When compared with PNL, one outstanding advantage of LPL is that it is harmless to the parenchyma. ${ }^{26}$ Therefore, the risk of bleeding is higher in PNL related to the access localization and dilation technique. Bleeding is the most important and frequent complication in PNL. In general, they are managed conservatively; however, arterial embolization may be required in some cases. Meria and col-

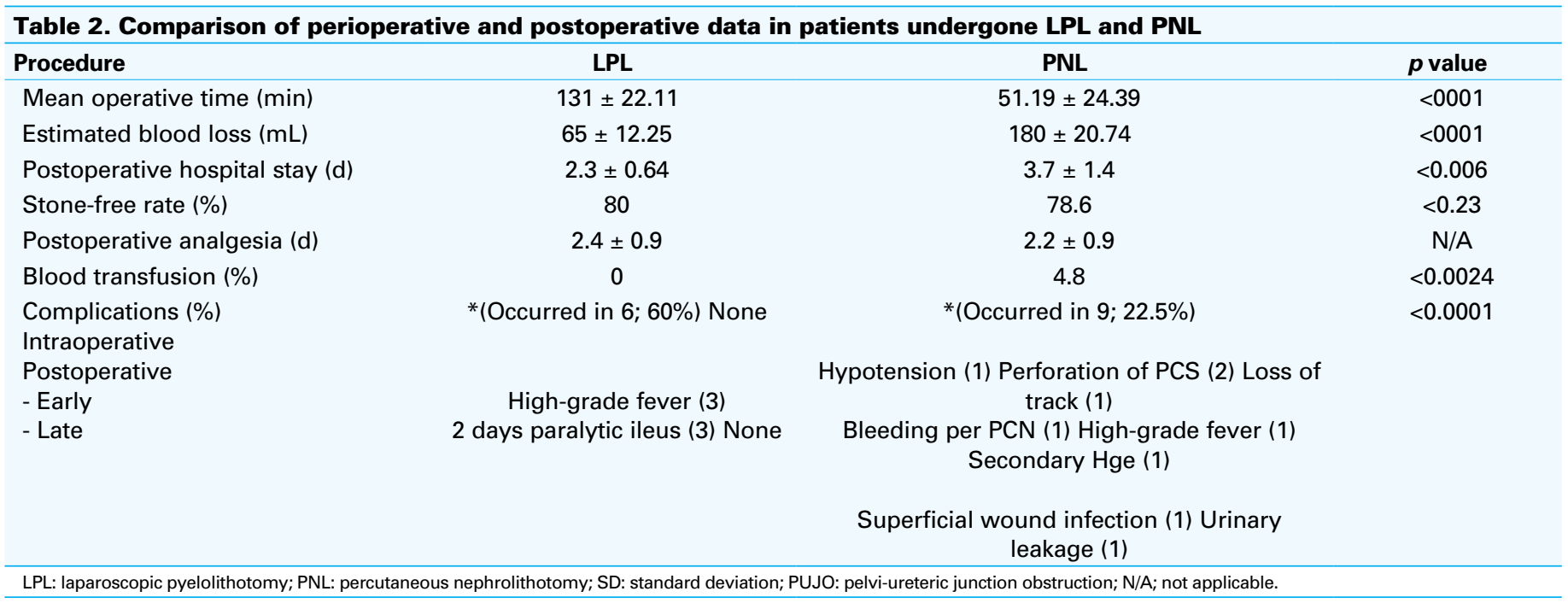


leagues ${ }^{21}$ compared PNL with LPL and found significant venous bleeding in 3 of the 16 patients managed with PNL and the estimated blood loss was more significant in the PNL group (70 vs. $210 \mathrm{~mL}$ ). Also in our study the mean blood loss was significantly less in the LPL group $(65 \pm 12.25$ vs. $180 \pm 20.74 \mathrm{~mL}$ ), with no need for blood transfusion in all the cases.

There was a statistically significant higher incidence of postoperative fever (9 patients) in the PNL group in comparison with the LPL group (3 patients). Postoperative fever is a common medical complication associated with PNL (23\%$25 \%),{ }^{27}$ and urosepsis develops in only a small fraction of these febrile patients (1\%-2\%). ${ }^{28} \mathrm{LPL}$ complications usually relate to the pyelotomy closure and the stone removal. Meria and colleagues ${ }^{21}$, Sinha and Sharma ${ }^{29}$ and Holman and colleagues $^{30}$ reported that urinary leakage after the procedure developed in $12.5 \%(2 / 16), 10 \%(2 / 20)$ and $7 \%(1 / 15)$ of patients, respectively.

Meria and colleagues ${ }^{21}$ reported an insignificant difference in the stone-free rate between LPL $(88 \%)$ and PNL $(82 \%)$. The high stone-free rate achieved in the current study was due to proper selection of cases, the intact removal of the stone in contrast to PNL in which disintegration of the stone by the pneumatic lithotripsy may have left some residuals, and the increased learning curve. ${ }^{18}$ Sinha and Sharma ${ }^{28}$ found that SWL or PNL was ideal in their study of 20 patients with LPL and with a single renal pelvic stone, yet these options were not available. They reported the feasibility of LPL in the management of a single renal pelvic stone, especially when the stone is not complicated. They defined this as a new indication for laparoscopy in a developing country. Tefekli and colleagues ${ }^{26}$ reported their experience with LPL in 26 patients with solitary pelvic stone in comparison with matched group of $\mathrm{PNL}$; their stone free rate was $100 \%$ and $88.4 \%$, respectively.

In our study, we preferred the transperitoneal approach to achieve the renal pelvis. Although the retroperitoneal approach allows direct access to the posterior aspect of the renal pelvis, avoids extensive dissection, avoids urine and blood leakage into the peritoneal space and consequently results in quicker postoperative recovery, we preferred the transperitoneal approach. This approach was more familiar to most of our surgeons, we had a much larger working space available, there are established anatomical landmarks for performing the surgery effectively and it has a shorter learning curve.

Tefekli and colleagues ${ }^{26}$ support our opinion and prefer the transperitoneal rather than the retroperitoneal approach for accessing the renal pelvis. They found that the retroperitoneal approach provides a limited working space for suturing and knot-tying in obese patients.

Although LPL appears to be more invasive because three or four trocar punctures are needed compared with PNL in which only a single hole is made, in PNL there is transgression of the renal parenchyma with its potential of various complications, such as nephron damage and bleeding. ${ }^{22}$ On most occasions, laparoscopy is nephron sparing, namely, pyelolithotomy compared with PNL. ${ }^{31}$ There is agreement about the role of laparoscopy in stone surgery by many authors, but in special situations, such as those associated with pelvi-ureteric junction obstruction, stone in the pelvic kidney and caliceal stones. ${ }^{22,24,32}$ Recently, Salvado and colleagues ${ }^{33}$ believe that this technique can be considered in cases of a large stone burden in different locations of the kidney.

\section{Conclusion}

Although laparoscopic surgery has gained a great acceptance as a standard management in many urological disorders, it will continue to play an extremely small role in the management of patients with nephrolithiasis. In addition, future improvements in endoscopic technology and the skills of contemporary urologists are likely to further narrow its application. Furthermore, LPL is associated with longer operating time, longer recuperation, more invasive, less cosmetic and requires more skills when compared to PNL. Laparoscopy is not suitable in patients with dense peripelvic adhesions, intrarenal pelvis or a history of previous abdominal surgery. However, LPL may be indicated in special situations, like ectopically located, congenitally anomalous kidneys or in patients where concomitant laparoscopic procedure is indicated, such as pyeloplasty. It can also be indicated in patients who have failed SWL, PNL and URS because LPL is potentially harmless to the renal parenchyma and is associated with less blood loss.

Competing interests: None declared.

This paper has been peer-reviewed.

\section{References}

1. Honeck $P$, Wendt-Nordahl $G$, Krombach $P$, et al. Does open stone surgery still play a role in the treatment of urolithiasis? Data of a primary urolithiasis center. J Endourol 2009;23:1209-12. http://dx.doi. org/10.1089/end.2009.0027

2. Paik ML, Wainstein MA, Sprinak JP, et al. Current indications of open surgery in treatment of renal and ureteral calculi. J Urol 1998;159:374-9. http://dx.doi.org/10.1016/S0022-5347(01)63922-3

3. Bichler KH, Lahme S, Strohmaier WL (1997) Indications for open stone removal of urinary calculi. Urol Int 1997;59:102-8. http://dx.doi.org/10.1159/000283037

4. Assimos DG, Boyce WH, Harrison LH, et al. The role of open stone surgery since extracorporeal shock wave lithotripsy. J Urol 1989;142:263-7.

5. Tiselius HG, Alken P, Buck C, et al. Guidelines on urolithiasis. European Association of Urology. http:// www.uroweb.org/gls/pdf/Urolithiasis\%202010.pdf. Accessed March 13, 2013.

6. Deger S, Tuellmann M, Schoenberger B, et al. Laparoscopic anatrophic nephrolithotomy. Scand I Urol Nephrol 2004;38:263-5. http://dx.doi.org/10.1080/00365590410028719

7. Simforoosh N, Aminsharifi A, Tabibi A, et al. Laparoscopic anatrophic nephrolithotomy for managing large staghorn calculi. BJU Int 2008;101:1293-6. http://dx.doi.org/10.1111/j.1464-410X.2008.07516.X 
8. Turna $B$, Umul $M$, Demiryoguran $S$, et al. How do increasing stone surface area and stone configuration affect overall outcome of percutaneous nephrolithotomy? J Endourol 2007;21:34-43. http://dx.doi. org/10.1089/end.2005.0315

9. Nadu A, Schatloff 0 , Morag R, et al. Laparoscopic surgery for renal stones: is it indicated in the modern endourology era? Int Braz J Urol 2009;35:9-17. http://dx.doi.org/10.1590/S167755382009000100003

10. Fernbach S, Maizels M, Conway JJ. Ultrasound grading of hydronephrosis: introduction to the system used by Society for Fetal Urology. Pediatr Radiol 1993;23:478-80. http://dx.doi.org/10.1007/ BF02012459

11. Lam HS, Lingeman JE, Russo R, et al. Stone surface area determination techniques: a unifying concept of staghorn stone burden assessment. J Urol 1992;48:1026-9.

12. Rassweiler JJ, Henkel TO, Stock C, et al. Retroperitoneal laparoscopic nephrectomy and other procedures in the upper retroperitoneum using a balloon dissection technique. Eur Urol 1994;25:229-233.

13. Teber D, Tefekli A, Eskicorapci S, Gozem AS, Bujosevic S, Sugiono M, Stock C, Rassweiler JJ (2006) Retroperitoneoscopy: a versatile access for many urologic indications. Eur Urol Supp (5):975-982

14. Tefekli A, Ali Karadag M, Tepeler K, et al. Classification of percutaneous nephrolithotomy complications using the modified Clavien grading system: looking for a standard. Eur Urol 2008:53:184-90. http:// dx.doi.org/10.1016/i.eururo.2007.06.049

15. Micali S, Moore RG, Averch TD, et al. The role of laparoscopy in the treatment of renal and ureteral calculi. J Urol 1997;157:463-6. http://dx.doi.org/10.1016/S0022-5347(01)65173-5

16. Goel A, Hemal AK. Evaluation of role of retroperitoneoscopic pyelolithotomy and its comparison with percutaneous nephrolithotripsy. Int Urol Nephrol 2003;35:73-6. http://dx.doi.org/10.1023/A:1025962009286

17. Hemal AK, Goel $A$, Kumar $M$, et al. Evaluation of laparoscopic retroperitoneal surgery in urinary stone disease. J Endourol 2001;15:701-5. http://dx.doi.org/10.1089/08927790152596271

18. Al-Hunayan A, Abdulhalim H, El-Bakry E, et al. Laparoscopic pyelolithotomy: Is the retroperitoneal route a better approach? Int J Urol 2009;16:181-6. http://dx.doi.org/10.1111/j.1442-2042.2008.02210.x

19. Al-Azaby H. Transperitoneal Laparoscopic Pyelolithotomy: Initial Experience. Benha MJ 2008;25:177-8.

20. Nouralizadeh A, Simforoosh N, Soltani MH, et al. Laparoscopic Transperitoneal Pyelolithotomy for Management of Staghorn Renal Calculi. J Laparoendosc Adv Surg Tech A 2012;22:61-5. http://dx.doi. org/10.1089/lap.2011.0302. Epub 2011 Dec 5.

21. Meria P, Milcent S, Desgrandchamps F et al., (2005): Management of pelvic stones larger than $20 \mathrm{~mm}$ : laparoscopic transperitoneal pyelolithotomy or percutaneous nephrolithotomy? Urol Int 2005;75:322-6. http://dx.doi.org/10.1159/000089167
22. GoelA, Hemal AK. Evaluation of role of retroperitoneoscopic pyelolithotomy and its comparison with percutaneous nephrolithotripsy. Int Urol Nephrol 2003;35:73-6. hittp://dx.doi.org/10.1023/A:1025962009286

23. Gaur DD, Agarwal DK, Purohit KC, et al. Retroperitoneal laparoscopic pyelolithotomy. J Urol 1994;151:9279.

24. Hemal AK, Goel A, Kumar $M$, et al. Evaluation of laparoscopic retroperitoneal surgery in urinary stone disease. J Endourol 2001;15:701-5. http://dx.doi.org/10.1089/08927790152596271

25. Kramer BA, Hammond L, Schwartz BF. Laparoscopic pyelolithotomy: Indications and technique. J Endourol 2007;21:860-1. http://dx.doi.org/10.1089/end.2006.0410

26. Tefekli A, Tepeler A, Akman T, et al. The comparison of laparoscopic pyelolithotomy and percutaneous nephrolithotomy in the treatment of solitary large renal pelvic stones. Urol Res 2012;40:549-55.

27. Wen C, Nakada SY. Treatment selection and outcomes: Renal calculi. Urol Clin North Am 2007;34:409-19. http://dx.doi.org/10.1016/i.ucl.2007.04.005

28. Mariappan P, Smith G, Bariol SV, et al. (2005) Stone and pelvic urine culture and sensitivity are better than bladder urine as predictors of urosepsis following percutaneous nephrolithotomy: A prospective clinical study. J Urol 2005;173:1610-4. http://dx.doi.org/10.1097/01.ju.0000154350.78826.96

29. Sinha R, Sharma N. Retroperitoneal laparoscopic management of urolithiasis. J Laparoendosc Adv Surg Tech A 1997;95-8. http://dx.doi.org/10.1089/lap.1997.7.95

30. Holman E, Munim Khan A, Pasztor I, et al. Simultaneous bilateral compared with unilateral percutaneous nephrolithotomy. Brit J Urol 2002;89:334. http://dx.doi.org/10.1046/i.1464-4096.2001.01521.x

31. Ramalingam M. Editorial comment on: Nadu A, Schatloff 0, Morag R, et al. Laparoscopic surgery for renal stones: Is it indicated in the modern endourology era? Int Braz I Urol 2009;35:9-18. http://dx.doi. org/10.1590/S1677-55382009000100003

32. Desai RA, Assimos DG. Role of laparoscopic stone surgery. Urology 2008;71:578-80. http://dx.doi. org/10.1016/j.urology.2007.10.052

33. Salvado JA, Guzma'n $\mathrm{S}$, Trucco $\mathrm{CA}$, et al. Laparoscopic pyelolithotomy: Optimizing surgical technique. J Endourol 2009;23:575-8. http://dx.doi.org/10.1089/end.2008.0582

Correspondence: Dr. Mohamed Etafy, Department of Urology, Mayo Clinic, Jacksonville, Florida 32224; mhamdan102@gmail.com 